\title{
mGluR1 and mGluR5 Synergistically Control Cholinergic Synaptic Transmission in the Thalamic Reticular Nucleus
}

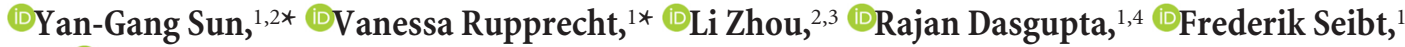 \\ and $\odot$ Michael Beierlein ${ }^{1,4}$ \\ ${ }^{1}$ Department of Neurobiology and Anatomy, McGovern Medical School, Houston, Texas 77030, ${ }^{2}$ Institute of Neuroscience, State Key Laboratory of \\ Neuroscience, CAS Center for Excellence in Brain Science and Intelligence Technology, Shanghai Institutes for Biological Sciences, Chinese Academy of \\ Sciences, Shanghai 200031, China, ${ }^{3}$ Graduate School, University of Chinese Academy of Sciences, Shanghai 200031, China, and ${ }^{4}$ University of Texas \\ Graduate School of Biomedical Sciences at Houston, Houston, Texas 77030
}

Acetylcholine $(\mathrm{ACh})$ signaling is involved in a wide range of processes, including arousal, attention, and learning. An increasing number of studies indicate that cholinergic control of these functions is highly deterministic, mediated by synaptic afferents that generate reliable and precise responses in postsynaptic neurons. However, mechanisms that govern plastic changes of cholinergic synaptic strength are poorly understood, even though they are likely critical in shaping the impact of cholinergic inputs on neuronal networks. We have recently shown that in the thalamic reticular nucleus (TRN), synaptic release of ACh generates excitatory-inhibitory biphasic postsynaptic responses, mediated by the activation of $\alpha 4 \beta 2$ nicotinic (nAChRs) and M2 muscarinic receptors (mAChRs), respectively. Here, using voltage-clamp recordings from TRN neurons in thalamocortical slices of mice, we demonstrate that the activation of Group I metabotropic glutamate receptors (mGluRs) by ambient or synaptically released glutamate evokes transient increases of nicotinic EPSCs. Additionally, we find that the selective Group I mGluR agonist DHPG [ $(S)$-3,5-dihydroxyphenylglycine] evokes long-term potentiation of nicotinic EPSCs (mGluR-nLTP), dependent on increases in postsynaptic $\mathrm{Ca}^{2+}$ concentration and the activation of phospholipase $\mathrm{C}$. Both the induction and the maintenance of mGluR-nLTP require synergistic activation of mGluR1 and mGluR5. Together, our results show that postsynaptic Group I mGluRs are critically involved in the regulation of cholinergic synaptic strength on different time scales, suggesting that cholinergic control of local thalamic circuits is highly context-dependent and regulated by the overall levels of glutamatergic afferent activity.

Key words: acetylcholine; basal forebrain; long-term plasticity; metabotropic glutamate receptor; synergistic; thalamic reticular nucleus

Significance Statement

Cholinergic signaling controls information processing and plasticity in neuronal circuits, but the mechanisms underlying the regulation of cholinergic synaptic strength on different time scales are unknown. Here we identify mGluR1 and mGluR5 as key elements in the dynamic regulation of cholinergic synaptic inputs onto neurons of the TRN. Our findings highlight potential mechanisms that regulate cholinergic signaling in the mammalian brain.

\section{Introduction}

Information processing in the thalamocortical system is regulated by cholinergic afferent projections originating in the basal forebrain $(\mathrm{BF})$ and the pedunculopontine/laterodorsal tegmental area of the brainstem (Zaborszky, 2002; Woolf and Butcher,

Received Feb. 5, 2016; revised June 4, 2016; accepted June 8, 2016

Author contributions: Y.-G.S., V.R., L.Z., R.D., F.S., and M.B. designed research; Y.-G.S., V.R., L.Z., R.D., and F.S. performed research; Y.-G.S., V.R., L.Z., R.D., F.S., and M.B. analyzed data; Y.-G.S., V.R., and M.B. wrote the paper.

This work was supported by National Natural Science Foundation of China Grants 31371122 and 81322015 to Y.-G.S. and National Institute of Neurological Disorders and Stroke Grant NSO77989 to M.B. R.D. was supported by a Zilkha Family Discovery Fellowship in Neuroengineering. We thank Dr. Hui-Chen Lu (Indiana University) for providing the mGluR5 knock-out mouse lines and for sharing unpublished data.
2011). Release of acetylcholine (ACh) from cholinergic afferents controls diverse cognitive functions, including learning and memory, sensory processing, and attention (Hasselmo and Sarter, 2011), whereas the loss of cholinergic neurons has been linked to Alzheimer's disease and to certain forms of dementia

The authors declare no competing financial interests.

*Y.-G.S. and V.R. contributed equally to this work.

Correspondence should be addressed to Dr. Michael Beierlein, Department of Neurobiology and Anatomy, McGovern Medical School, 6431 Fannin, Suite 7.046, Houston, TX 77030. E-mail: michael.beierlein@uth.tmc.edu.

V. Rupprecht's present address: Neurophysiology, Institute of Zoology, University of Regensburg, Universitätsstraße 31, 93040 Regensburg, Germany.

DOI:10.1523/JNEUROSCI.0409-16.2016

Copyright $\odot 2016$ the authors $\quad 0270-6474 / 16 / 367886-11 \$ 15.00 / 0$ 
(Whitehouse et al., 1982). Recent studies have led to important insights into the cellular mechanisms and functional consequences of cholinergic signaling in the thalamocortical system. Collectively, these studies have shown that synaptically released ACh can act with high temporal precision, by rapidly and reliably activating both nicotinic (nAChRs) and muscarinic (mAChRs) receptors expressed by specific types of neurons (Arroyo et al., 2014; Muñoz and Rudy, 2014). As a consequence, cholinergic inputs control synaptic plasticity (Gu and Yakel, 2011) and postsynaptic neuronal activity (Arroyo et al., 2012; Sun et al., 2013), in turn leading to specific and transient effects on neuronal circuits that underlie learning or sensory processing (Letzkus et al., 2011; Pinto et al., 2013; Eggermann et al., 2014; Hangya et al., 2015).

Despite the importance of the cholinergic system in mediating a number of diverse computations, the mechanisms that regulate cholinergic synaptic strength over distinct time scales remain poorly understood. Cholinergic action in postsynaptic targets is undoubtedly shaped by the temporal dynamics of presynaptic afferent activity. Neuronal firing patterns of cholinergic neurons in the $\mathrm{BF}$ and the brainstem vary as a function of sleep-wake cycle state and arousal (Lee et al., 2005; Hassani et al., 2009; Boucetta et al., 2014). In addition, BF neuronal activity can be tightly linked to the occurrence of salient stimuli (Hangya et al., 2015), allowing for the rapid and precise control of large cortical target regions, mediated by axonal afferents that form extensive arborizations across all layers of multiple columns (Wu et al., 2014). Short- or long-term changes in synaptic strength might allow for additional flexibility in cholinergic function. Studies in prefrontal cortex have suggested that glutamatergic synaptic inputs can trigger local and brief cholinergic transients by activating presynaptic receptors expressed by cholinergic terminals (Sarter et al., 2014), potentially enabling more specific control of cortical function. However, how neurotransmitters, such as glutamate or GABA, modulate cholinergic synaptic strength has never been explored in any detail.

Here we have addressed this question by exploring the glutamate-mediated regulation of cholinergic synapses targeting neurons in the thalamic reticular nucleus (TRN). The TRN is a major source of inhibition for first- and higher-order thalamic nuclei (Pinault, 2004) and is critically involved in the generation of certain forms of rhythmic activity, such as sleep spindles (Kim et al., 1997; Halassa et al., 2011) and in mediating attentional processes (McAlonan et al., 2006; Wimmer et al., 2015). Synaptic release of $\mathrm{ACh}$ in the TRN is mediated at least in part by afferents from the BF (Pita-Almenar et al., 2014; Ni et al., 2016) and leads to short-latency excitatory-inhibitory (E-I) biphasic postsynaptic responses, mediated by the activation of postsynaptic $\alpha 4 \beta 2$ nAChRs and M2 mAChRs, respectively (Sun et al., 2013). Both glutamatergic afferents from cortical layer 6 and cholinergic afferents are thought to target distal dendrites of TRN neurons, raising the possibility that changes in glutamate levels could regulate cholinergic synaptic strength. Our studies reveal that the activation of postsynaptic mGluRs expressed in TRN neurons plays a critical role in regulating cholinergic signaling on short and long time scales.

\section{Materials and Methods}

Slice preparation. Mice of either sex of the following strains were used: wild-type (WT) C57BL/6J, mGluR5 ${ }^{-/-}$, GABAergic neuron-specific mGluR5 knock-out, and Ntsr1-Cre $/$ Rosa-ChR2 ${ }^{+/-}$. GABAergic neuron-specific mGluR5 knock-out mice were generated by crossing distal-less homeobox 5/6-Cre (DLX-Cre) transgenic mice (The Jackson Laboratory, stock \#008199) with $m G l u R 5^{f f f}$ mice. In DLX-Cre animals, the expression of Cre recombinase is restricted to GABAergic neurons in the striatum and forebrain (Monory et al., 2006; Chao et al., 2010). Ntsr1-Cre ${ }^{+} / \mathrm{Rosa}-\mathrm{ChR} 2^{+/-}$mice were generated by crossing Ntsr1-Cre mice (MMRRC, 030648-UCD) with Rosa-ChR2 mice (The Jackson Laboratory, stock \#012569). In Ntsr1-Cre mice, the expression of Cre recombinase is restricted to a subpopulation of cortical layer 6 neurons (Bortone et al., 2014).

Thalamocortical slices $(400 \mu \mathrm{m})$ were prepared from young mice (P13-P18) as described previously (Agmon and Connors, 1991). Animals were anesthetized with isoflurane and decapitated, following protocols in accordance with National Institutes of Health guidelines and approved by institutional animal welfare committees. Slices were cut in an ice-cold sucrose-containing solution consisting of the following (in $\mathrm{mm}$ ): 234 sucrose, $2.5 \mathrm{KCl}, 1.25 \mathrm{NaH}_{2} \mathrm{PO}_{4}, 10 \mathrm{MgSO}_{4}, 26 \mathrm{NaHCO}_{3}, 10$ glucose, and $0.5 \mathrm{CaCl}_{2}$, bubbled with $95 \% \mathrm{O}_{2}-5 \% \mathrm{CO}_{2}$, using a vibratome (Leica VT1200S) at slicing speed of $0.2 \mathrm{~mm} / \mathrm{s}$ and a blade vibration amplitude of $0.8 \mathrm{~mm}$. Slices were incubated at $34^{\circ} \mathrm{C}$ for $45 \mathrm{~min}$ in solution containing the following (in $\mathrm{mM}$ ): $126 \mathrm{NaCl}, 26 \mathrm{NaHCO}_{3}, 2.5 \mathrm{KCl}, 1.25$ $\mathrm{NaH}_{2} \mathrm{PO}_{4}, 10$ glucose, $2 \mathrm{CaCl}_{2}$, and $2 \mathrm{MgCl}_{2}$. Slices were allowed to recover at room temperature for at least $30 \mathrm{~min}$ before recordings.

Electrophysiology. Slices were mounted on glass coverslips coated with poly-L-lysine (Sigma) and placed in a submerged chamber (Warner Instruments) attached to an upright Olympus BX51WI microscope (Olympus Optical) and perfused $(3 \mathrm{ml} / \mathrm{min}$ ) using a Minipulse 3 pump (Gilson). All recordings were performed at near-physiological temperatures $\left(32-34^{\circ} \mathrm{C}\right)$ using an in-line heater (Warner Instruments). Wholecell voltage-clamp recordings from TRN neurons were obtained under visual control in infrared-differential interference contrast mode using a CCD camera (Hamamatsu). Recording pipettes (2-4 $\mathrm{M} \Omega$ ) were filled with an internal solution containing the following (in $\mathrm{mM}$ ): 120 $\mathrm{CsMeSO}_{3}, 10 \mathrm{CsCl}, 10$ HEPES, 11 EGTA, $1 \mathrm{MgCl}_{2}, 1 \mathrm{CaCl}_{2}, 2 \mathrm{Mg}$-ATP, $0.3 \mathrm{Na}-\mathrm{GTP}$, and $1 \mathrm{QX}-314$, adjusted to $295 \mathrm{mOsm}$ and $\mathrm{pH}$ 7.3. For experiments in which intracellular $\mathrm{Ca}^{2+}$ levels were clamped at 50-100 $\mathrm{nM}$, the internal solution contained the following (in mM): $20 \mathrm{Cs}_{4}$ BAPTA, $102 \mathrm{CsMeSO}_{3}, 10 \mathrm{CsCl}, 2 \mathrm{MgCl}_{2}, 4 \mathrm{CaCl}_{2}, 10$ HEPES, $2 \mathrm{Mg}$-ATP, 0.4 $\mathrm{Na}-\mathrm{GTP}$, and 1 QX-314. For recordings of biphasic or isolated mAChRmediated responses, the internal solution contained the following (in mm): 120 KGluc, $10 \mathrm{KCl}, 10 \mathrm{HEPES}, 11 \mathrm{EGTA}, 1 \mathrm{MgCl}_{2}, 1 \mathrm{CaCl}_{2}, 2$ $\mathrm{Mg}$-ATP, and 0.3 Na-GTP, adjusted to $295 \mathrm{mOsm}$ and $\mathrm{pH}$ 7.3. Neurons were voltage-clamped at $-70 \mathrm{mV}$, and recordings were discarded if the series resistance $(<20 \mathrm{M} \Omega)$ changed by $>20 \%$. Cholinergic synaptic responses were evoked by stimulating afferents with patch pipettes (tip diameter: 5-8 $\mu \mathrm{m}$ ) filled with ACSF and placed locally in the TRN (100$200 \mu \mathrm{m}$ from the recorded cell). Stimulation intensities ranged from 7 to $62 \mu \mathrm{A}$ (stimulus duration, $200 \mu \mathrm{s}$ ), and stimuli were typically applied every $12 \mathrm{~s}$. Optical stimulation of corticothalamic (CT) afferents expressing ChR2 was performed using an LED $\left(475 \mathrm{~nm}, 3 \mathrm{~mW} / \mathrm{mm}^{2}\right)$ coupled to a dry objective $(4 \times$, NA 0.13$)$.

Experiments were performed in the presence of NBQX $(10 \mu \mathrm{M})$, 3-[( $R$ )-2-carboxypiperazin-4-yl]-propyl-1-phosphonic acid (R-CPP; 5 $\mu \mathrm{M})$, picrotoxin $(50 \mu \mathrm{M})$, and CGP55845 (5 $\mu \mathrm{M})$ to block AMPARs, NMDARs, $\mathrm{GABA}_{\mathrm{A}}$ Rs, and $\mathrm{GABA}_{\mathrm{B}}$ Rs, respectively. Unless noted, the bath solution included atropine $(10 \mu \mathrm{M})$ to block mAChRs. For experiments using the phospholipase C (PLC) inhibitor U73122, slices were incubated in ACSF containing U73122 ( $5 \mu \mathrm{M})$ for $1 \mathrm{~h}$. Recordings were performed in the continuous presence of U73122 (5 $\mu \mathrm{M})$.

NBQX, R-CPP, picrotoxin, CGP55845, LY 341495, 7-(Hydroxyimino)cyclopropachromen-1a-carboxylate ethyl ester (CPCCOEt), 2-Methyl-6-(phenylethynyl)pyridine hydrochloride (MPEP), (RS)2-Chloro-5-hydroxyphenylglycine (CHPG), DL-threo- $\beta$-Benzyloxyaspartic acid (TBOA), Dihydro- $\beta$-erythroidine hydrobromide $(\mathrm{DH} \beta \mathrm{E})$, and U73122 were purchased from Tocris Cookson. BAPTA was obtained from Invitrogen. All other chemicals were obtained from Sigma-Aldrich.

Data acquisition and analysis. Data were acquired using pClamp software (Molecular Devices). Recordings were filtered at $3 \mathrm{kHz}$ and digitized at $20 \mathrm{kHz}$ with a 16-bit analog-to-digital converter (Digidata 1440A, Molecular Devices). Data analysis was performed using custom-macros written in Igor Pro (Wavemetrics). Postsynaptic current (PSC) ampli- 
A

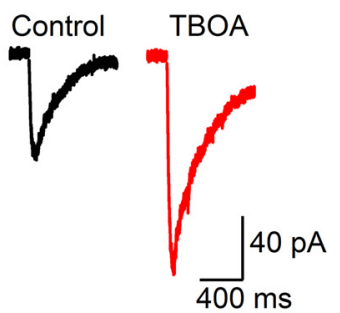

B

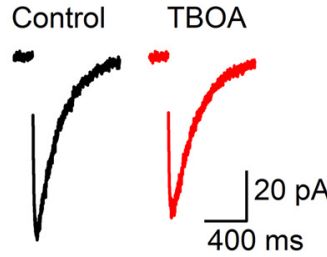

C

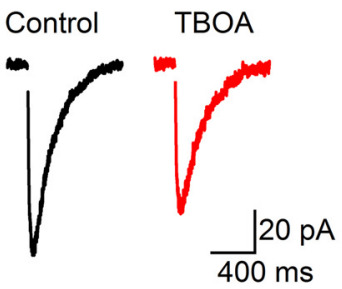

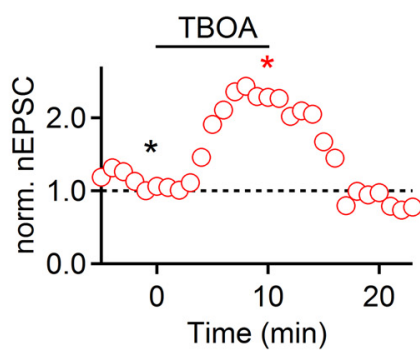
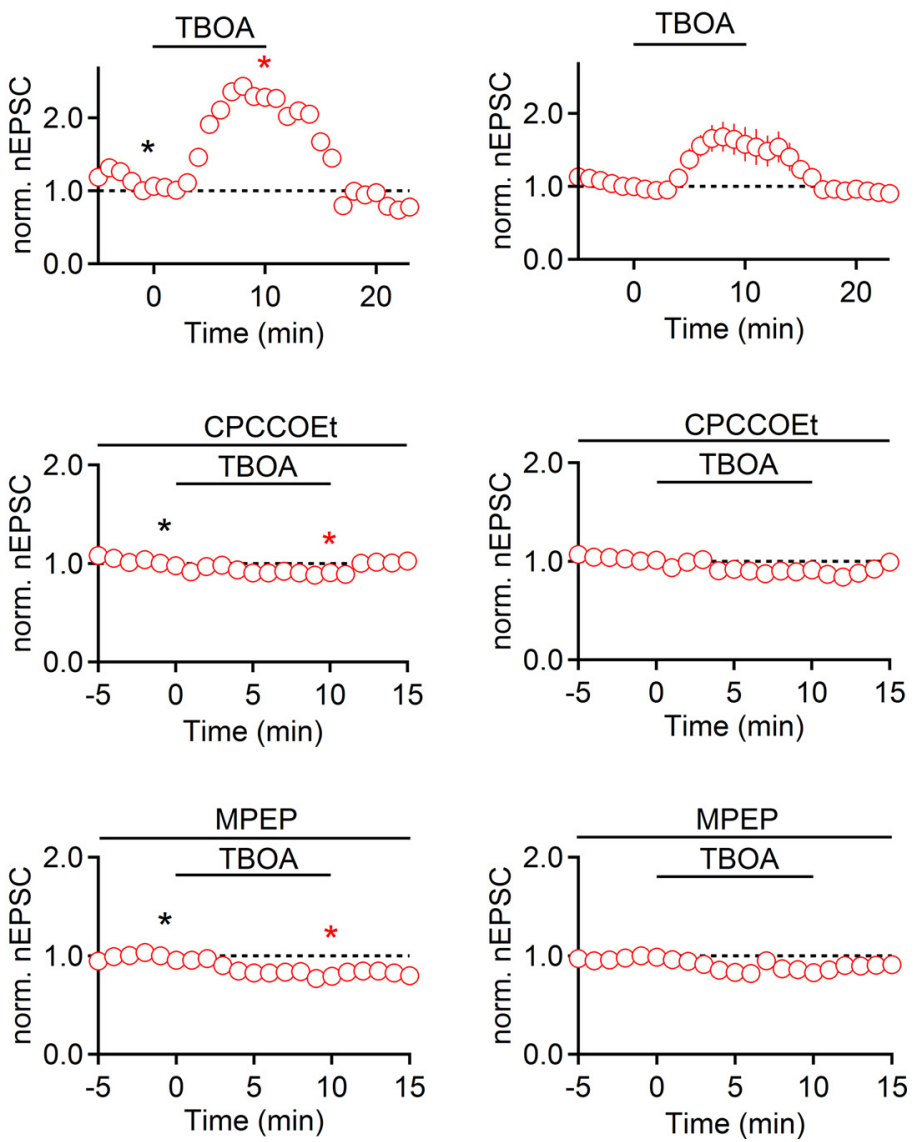

Figure 1. Increases in endogenous glutamate levels enhance cholinergic synaptic signaling. TRN neurons were recorded with a (s-based internal solution in the presence of atropine (10 $\mu \mathrm{M})$. $\boldsymbol{A}$, Bath application of the glutamate transporter blocker TBOA (100 $\mu \mathrm{M}, 10 \mathrm{~min})$ led to a reversible increase in nEPSC amplitude $(n=5) . B, C$, TBOA did not lead to $\mathrm{nEPSC}$ increase in the presence of either the mGluR1 antagonist (PCCOEt $(100 \mu \mathrm{m}, n=5 ; \boldsymbol{B})$ or the mGluR5 antagonist MPEP $(50 \mu \mathrm{m}, n=5 ; \boldsymbol{C})$. $\boldsymbol{A}-\boldsymbol{C}$, Left, Representative nEPSCs recorded in control (black) and in TBOA (red) are shown for each condition. $\boldsymbol{A}-\boldsymbol{C}$, Middle, Representative experiments show time course of $n E P S C$ during TBOA application. Individual values are averages over 5 consecutive time points. ${ }^{*}$ Time points of EPSC recordings shown on left. $\boldsymbol{A}-\boldsymbol{C}$, Right, Summary data, expressed as mean \pm SEM.

tudes for each recording were binned in 1 min segments and normalized to the average PSC amplitude obtained during the baseline period just before drug application, unless stated otherwise. LTP magnitude was determined from a 5 min period between 25 and 30 min after induction and normalized to the PSC amplitude measured in a 5 min period just before LTP induction. Data were analyzed with two-way ANOVA and Student's unpaired or paired $t$ test, and significance was taken as $p<0.05$. All data are expressed as mean \pm SEM.

\section{Results}

Increases in ambient glutamate enhance nicotinic synaptic strength via activation of mGluR1 and mGluR5

To examine mechanisms regulating cholinergic synaptic strength, we performed whole-cell voltage-clamp recordings from TRN neurons in thalamocortical slices of mice. Cholinergic synaptic inputs were activated electrically using glass electrodes placed locally in the TRN, in the presence of antagonists for fast glutamatergic and GABAergic receptors, as described previously (Sun et al., 2013). To isolate nicotinic EPSCs (nEPSCs), recordings were performed using a Cs-based internal solution unless reported otherwise. We first examined the effects of enhancing endogenous glutamate levels on cholinergic transmission by applying the glutamate transporter inhibitor TBOA. Bath application of TBOA $(100 \mu \mathrm{M})$ for $10 \mathrm{~min}$ led to a rapid and reversible increase in nEPSC amplitude $(153 \pm 21 \%$ of baseline at $t=10 \mathrm{~min}, n=5, p=0.069$, paired $t$ test; Fig. $1 A$ ). To determine whether TBOA-induced enhancement of nEPSC is mediated by activation of mGluRs, we repeated these experiments in the presence of either the mGluR1 antagonist CPCCOEt $(100 \mu \mathrm{M})$ or the mGluR5 antagonist MPEP $(50 \mu \mathrm{M})$. Under both conditions, TBOA-induced nEPSCs increases were completely blocked (CPCCOEt: $86 \pm 3 \%$ of baseline at $t=10 \mathrm{~min}, n=5, p=0.030$; Fig. $1 B$; MPEP: $84 \pm 2 \%$ at $t=10 \mathrm{~min}, n=5, p=0.034$, unpaired $t$ test; Fig. 1C). By contrast, the Group II mGluR antagonist LY $341495(200 \mathrm{nM})$ did not significantly influence TBOAinduced increases in nEPSC amplitude $(151 \pm 15 \%$ of baseline, $t=10 \mathrm{~min}, n=5, p=0.93$, unpaired $t$ test; data not shown). These data indicate that increases in endogenous glutamate levels can rapidly and reversibly enhance cholinergic neurotransmission, mediated by the synergistic activation of mGluR1 and mGluR5.

Activation of postsynaptic Group I mGluRs can lead to $\mathrm{Ca}^{2+}$ release from internal stores and the activation of PLC. To examine whether this pathway is involved in TBOAinduced enhancement in cholinergic transmission, we recorded neurons with an internal solution containing the $\mathrm{Ca}^{2+}$ chelator BAPTA $(20 \mathrm{~mm})$ to hold postsynaptic $\mathrm{Ca}^{2+}$ levels at 50-100 nM. Under these conditions, TBOA still led to an increase in nEPSC amplitude (197 $\pm 28 \%$ of baseline at $t=10$ min, $n=5, p<0.001$, paired $t$ test; data not shown). Similarly, for slices incubated in ACSF containing the PLC antagonist U73122 $(5 \mu \mathrm{M})$, TBOA led to increases in nEPSC amplitude ( $163 \pm 10 \%$ of baseline at $t=10 \mathrm{~min}, n=6, p<0.001$, paired $t$ test; data not shown). Together, these data indicate that tran- 

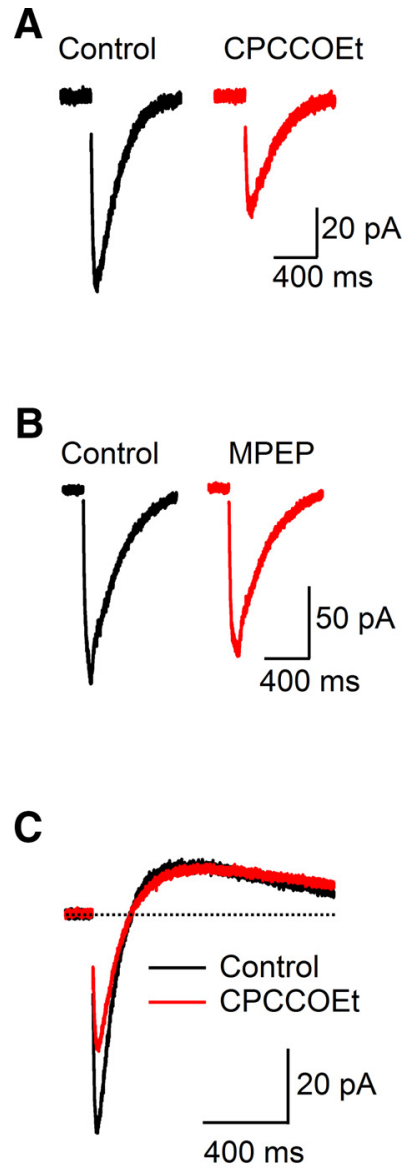
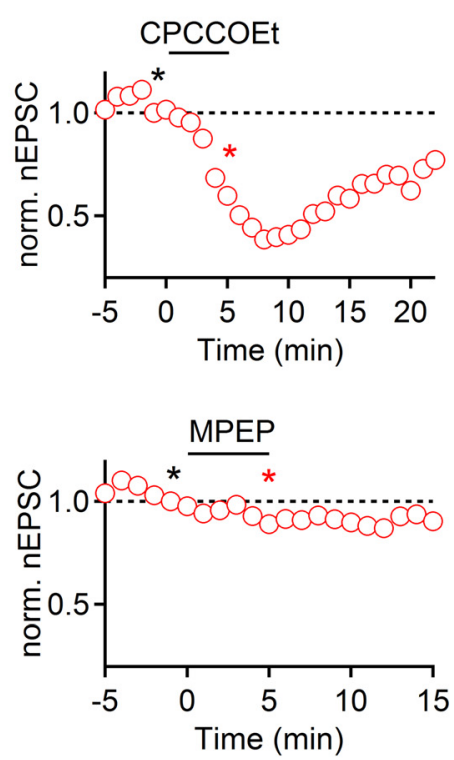

D

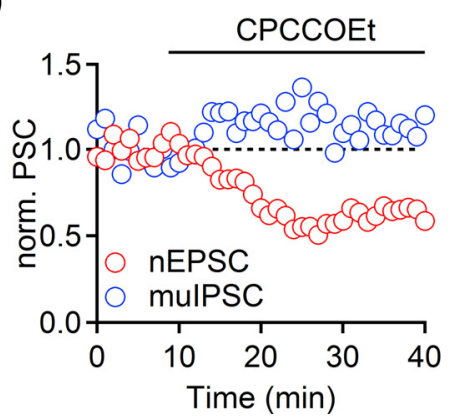

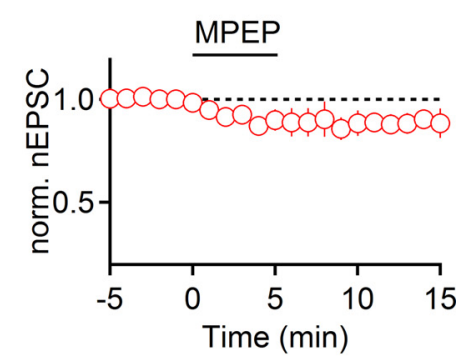
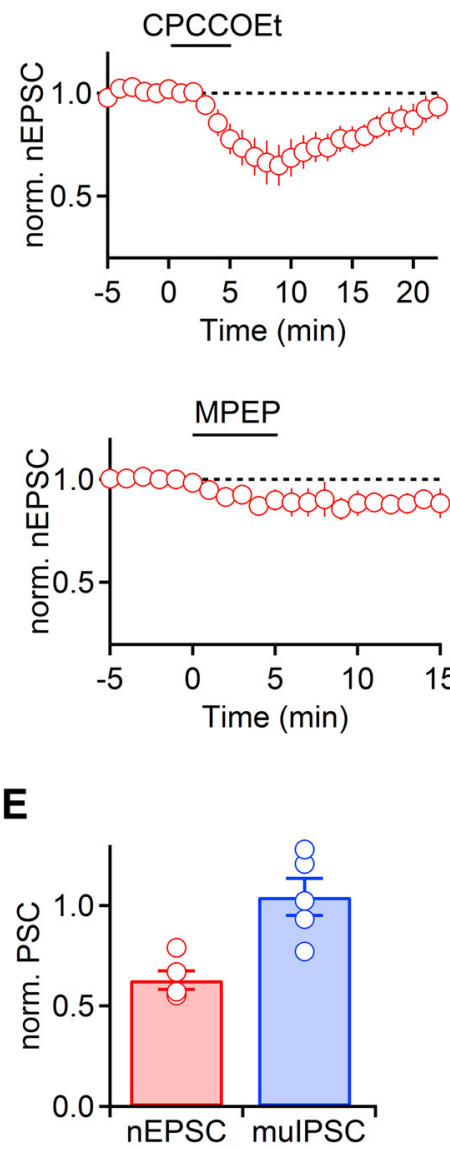

Figure 2. Persistent mGluR1 activity enhances nicotinic synaptic signaling. $A, n E P S C$ amplitude was reversibly reduced following bath application of the mGluR1 antagonist CPCCOEt (100 $\mu$ M, 5 $\min , n=5$ ) Recordings were obtained using a (s-based internal solution. $\boldsymbol{B}$, Bath application of mGluR5 antagonist MPEP ( $50 \mu \mathrm{M}, 5 \mathrm{~min}$ ) led to a modest reduction of $n$ EPSC amplitude ( $n=5$ ). $\boldsymbol{A}$, $\boldsymbol{B}$, Left, Representative $\mathrm{nEPSC}$ recorded in control (black) and following mGluR antagonist application (red). $\boldsymbol{A}, \boldsymbol{B}$, Middle, Representative experiments show time course of nEPSC during drug application. Individual values are averages over 5 consecutive time points. *Time points of EPSC recordings shown on left. $\boldsymbol{A}, \boldsymbol{B}$, Right, Summary data, expressed as mean \pm SEM. $\boldsymbol{C}-\boldsymbol{E}$, Persistent mGluR1-mediated enhancement of cholinergic signaling is limited to nicotinic component. Recordings were obtained using a K-based internal solution. $C$, Representative traces showing biphasic cholinergic response before (black) and following bath application of CPCCOEt (red). D, Time course of nEPSC (red) and mulPSC (blue) during wash-in of CPCCOEt for a representative experiment, with $\mathrm{nEPSC}$ and muIPSC values averaged over 5 consecutive time points and normalized to their respective control values. $\boldsymbol{E}$, Summary data $(n=5)$ show $\mathrm{nEPSC}$ (red) and mulPSC (blue) in CPCCOEt, normalized to their respective control values before CPCCOEt wash-in.

sient increases in nEPSC amplitude are triggered by Group I mGluR activation but do not involve increases in postsynaptic $\mathrm{Ca}^{2+}$ or the activation of PLC.

\section{Persistently active mGluR 1 enhances nicotinic synaptic signaling in the TRN}

Previous studies have shown that ambient levels of extracellular glutamate (Chanda and Xu-Friedman, 2011; Crabtree et al., 2013) or changes in receptor properties (Young et al., 2013) can mediate a persistent activation of mGluRs. As previous reports have documented activation of NMDARs (Zhang et al., 2009) and mGluRs (Crabtree et al., 2013) by ambient glutamate levels in the TRN in vitro, we examined whether mGluR activation can control cholinergic synaptic strength, even under baseline conditions. We found that bath application of CPCCOEt to block mGluR1 (100 $\mu \mathrm{M}, 5$ min) significantly decreased nEPSC amplitudes in a reversible manner $(78 \pm 7 \%$ of baseline, $t=5 \mathrm{~min}, n=5, p=0.017$, paired $t$ test; Fig. 2A). By contrast, bath application of MPEP to block mGluR5 (100 $\mu \mathrm{M}, 5 \mathrm{~min}$ ) only led to a modest reduction of nEPSC amplitude that was not statistically significant $(89 \pm 5 \%$ of baseline, $t=5 \mathrm{~min}$, $n=5, p=0.071$, paired $t$ test; Fig. $2 B$ ).
ACh release in the TRN evokes biphasic postsynaptic responses by activating both nAChRs and mAChRs (Sun et al., 2013). To further examine the specificity of the mGluR1-mediated regulation of cholinergic neurotransmission, we recorded biphasic cholinergic postsynaptic responses in voltage clamp using a K-based internal solution. Consistent with the above results, CPCCOEt application led to a significant decrease of nEPSCs ( $63 \pm 5 \%$ of baseline, $t=8$ min, $n=5, p=0.002$, paired $t$ test; Fig. $2 C-E$ ). By contrast, muscarinic IPSCs (muIPSCs) were unaffected under these conditions (104 $\pm 9 \%$ of baseline, $t=8 \mathrm{~min}, n=5, p=0.68$, paired $t$ test; Fig. $2 C-E)$. Together, these data indicate that tonic mGluR1 activation specifically enhances nicotinic signaling under baseline conditions. The mechanism for this enhancement was not further investigated.

\section{Activation of CT afferents enhances cholinergic synaptic signaling in the TRN}

Our results described so far point to a critical role of Group I mGluRs in regulating cholinergic signaling, raising the question of whether the release of glutamate from afferent projections to TRN can control cholinergic synaptic signaling via a heterosynaptic mechanism. In the TRN, Group I mGluRs are thought to be expressed in distal 
A

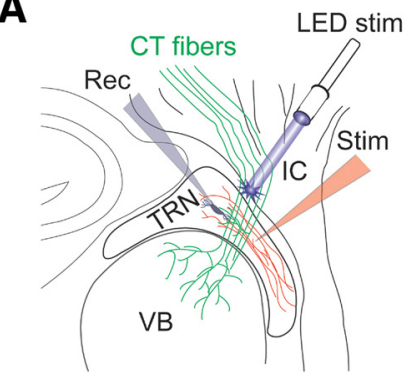

C

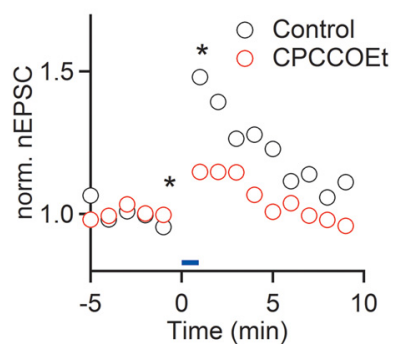

B

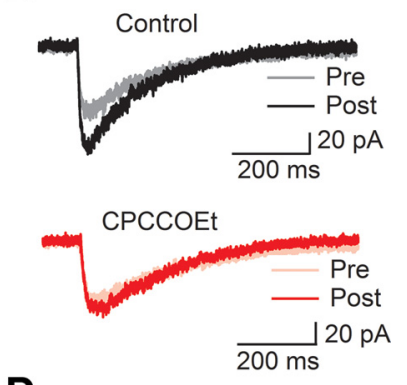

D

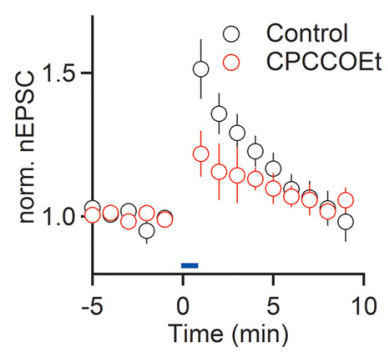

Figure 3. CT afferent activity enhances nicotinic synaptic signaling. $A$, Schematic of recording configuration. Cholinergic afferents to TRN (red) were activated using glass electrodes, before and following optical activation of ChR2-expressing CT afferents (green) with stimulus trains (10 pulses of 1 ms duration, at $20 \mathrm{~Hz}$ ) once every second for $1 \mathrm{~min}$. $\boldsymbol{B}$, Representative recordings comparing $n E P S C s$ before (Pre) and immediately following CT stimulation (Post), in control (top) and with CPCCOEt in the bath (bottom). C, Time course of nEPSC amplitude before and following optical CT activation (blue bar), in control (black circles) and in the presence of CPCCOEt (red circles), for the same recordings shown in $\boldsymbol{B}$. * Time points of recordings shown in B. D, Summary data show time course of CT-evoked $n E P S C$ enhancement in control (black circles, $n=6$ neurons) and in the presence of (PCCOEt (red circles, $n=5$ neurons). Blue bar represents duration of $\mathrm{CT}$ activation.

dendrites (Godwin et al., 1996), which are the targets of extensive CT feedback projections from layer 6 (Jones, 2007) as well as cholinergic afferents from the BF and the brainstem (Hallanger and Wainer, 1988). Previous studies have demonstrated activation of Group I mGluRs by trains of glutamatergic afferent activity (Long et al., 2004; Landisman and Connors, 2005). To examine whether the synaptic activation of mGluRs can lead to changes in cholinergic synaptic strength, we performed experiments using Ntsr1-Cre $e^{+}$Rosa$C h R 2^{+/-}$mice that specifically express ChR2 in CT projections (Fig. $3 A$ ). We found that wide-field optical activation of CT fibers with 20 $\mathrm{Hz}$ stimulus trains for $1 \mathrm{~min}$ led to a rapid and transient increase in nEPSC amplitude ( $151 \pm 8 \%$ of baseline, $n=6, p<0.001$, paired $t$ test; Fig. $3 B-D$ ), with nEPSCs returning to baseline levels after $\sim 10$ min. To determine the involvement of Group I mGluRs, we repeated these experiments in the presence of CPCCOEt and found that CTevoked nEPSC amplitude increases were significantly smaller compared with control ( $122 \pm 8 \%$ of baseline, $n=5, p=0.026$, two-way ANOVA; Fig. $3 B-D$ ). These data indicate that mGluR1 recruited by CT afferent activity mediates heterosynaptic potentiation at cholinergic synapses onto TRN neurons.

\section{Activation of Group I mGluRs induces long-term potentiation of nicotinic synaptic signaling}

In an effort to better understand the mechanisms underlying Group I mGluR-mediated increases in nEPSCs, we recorded isolated nicotinic responses using a Cs-based internal solution and bath-applied the Group I mGluR agonist ( $S$ )-3,5-dihydroxyphenylglycine (DHPG; $50 \mu \mathrm{M}$ ) for $5 \mathrm{~min}$. We found that DHPG application led to a rapid enhancement of nEPSCs (167 \pm $12 \%$ compared with control, $t=5 \mathrm{~min}, n=12, p=0.007$, paired

$t$ test). However, in contrast to our results using TBOA or CT activation, nEPSCs remained elevated following DHPG wash-out $(t=26-30 \mathrm{~min}, 167 \pm 11 \%$ compared with control, $n=12 ; p<$ 0.001 , paired $t$ test). For recordings that were stable for at least 40 min following DHPG application, nEPSCs remained potentiated $(t=36-40 \mathrm{~min}, 165 \pm 8 \%$ compared with control, $n=7, p=$ 0.001 , paired $t$ test; Fig. $4 A$ ). In contrast, application of a lower dose of DHPG ( $25 \mu \mathrm{M}$ for $5 \mathrm{~min}$ ) only led to a transient increase in nEPSC amplitude, with nEPSC amplitudes returning to baseline levels within 15 min following DHPG application (data not shown). Thus, activation of Group I mGluRs using DHPG can lead to a persistent increase in cholinergic synaptic strength.

Long-term changes in cholinergic synaptic strength could be expressed either presynaptically or postsynaptically. Any increases in ACh release should result in an enhancement of both nEPSC and muIPSC, whereas a lack of muIPSC enhancement would be indicative of a postsynaptic expression mechanism. To distinguish between these possibilities, we attempted to record cholinergic biphasic responses and to quantify DHPG-induced changes of nAChR- and mAChR- mediated components in the same neuron. However, this approach proved impractical, due to poor voltage clamp of large-amplitude nEPSCs using a K-based internal solution. We therefore recorded isolated muIPSCs using a K-based internal solution in the presence of the nAChR antagonist $\mathrm{DH} \beta \mathrm{E}$ ( $500 \mathrm{nM})$. DHPG application $(50 \mu \mathrm{M}$ for $5 \mathrm{~min}$ ) did not lead to a persistent change in amplitude of muIPSC (109 \pm $7 \%$ of baseline, $t=26-30 \mathrm{~min}, n=7, p=0.15$, paired $t$ test; Fig. $4 B)$. To confirm that the observed long-term enhancement of nicotinic signaling was not limited to recordings obtained using a Cs-based internal solution, we recorded small-amplitude isolated nEPSCs with a K-based internal solution in the presence of atropine $(10 \mu \mathrm{M})$. DHPG still led to reliable and persistent increases of nEPSC under these conditions (160 $\pm 6 \%$ of baseline, $t=$ 26-30 $\min , n=2$; data not shown).

It remains possible that DHPG-induced changes in cholinergic signaling are at least in part mediated by persistent increases in release probability $p$, which are not reported as changes in muIPSC amplitude, due to saturation of postsynaptic mAChRs. To address this possibility, we quantified changes in nEPSC and muIPSC amplitudes following increases in external $\mathrm{Ca}^{2+}$ concentration from 2 to $3 \mathrm{~mm}$ to enhance $p$ at cholinergic synapses. This treatment resulted in increases in nEPSCs ( $147 \pm 6 \%$ of baseline, $n=5$; Fig. $4 C$ ), comparable with the long-term nEPSC enhancement following DHPG application. Under the same conditions, muIPSCs showed similar amplitude increases $(137 \pm 7 \%$ of baseline, $n=5$; Fig. $4 C$ ), indicating that both nEPSC and muIPSC amplitudes are sensitive measures of increases in $p$.

Together, these data suggest that increases in cholinergic synaptic transmission following DHPG application are not accompanied by substantial increases in $p$ but are primarily mediated by a postsynaptic mechanism restricted to nAChR signaling. In the following, we will refer to this form of plasticity as mGluR-dependent nicotinic long-term potentiation (mGluR-nLTP).

\section{mGluR-nLTP requires activation of PLC and increases in postsynaptic $\mathrm{Ca}^{2+}$}

Several forms of long-term plasticity at glutamatergic synapses throughout the brain are mediated by the activation of PLC and the release of $\mathrm{Ca}^{2+}$ from internal stores (Gladding et al., 2009; Lüscher and Huber, 2010). To determine the involvement of PLC in mGluR-nLTP, we performed recordings in slices prein- 
A

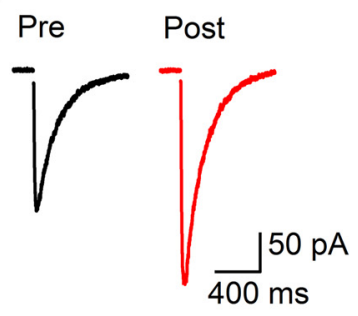

B

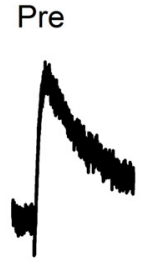

Post

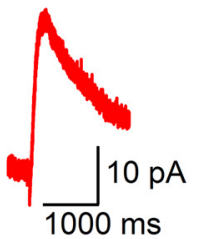

C

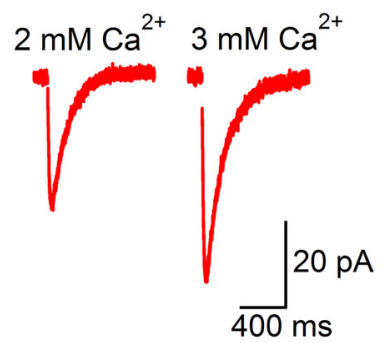

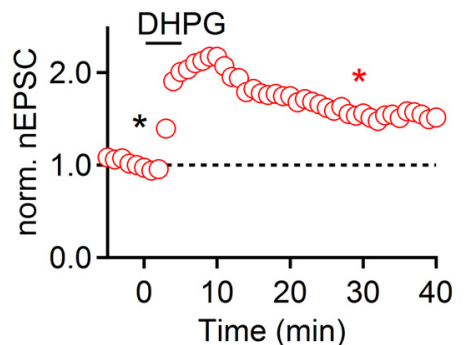
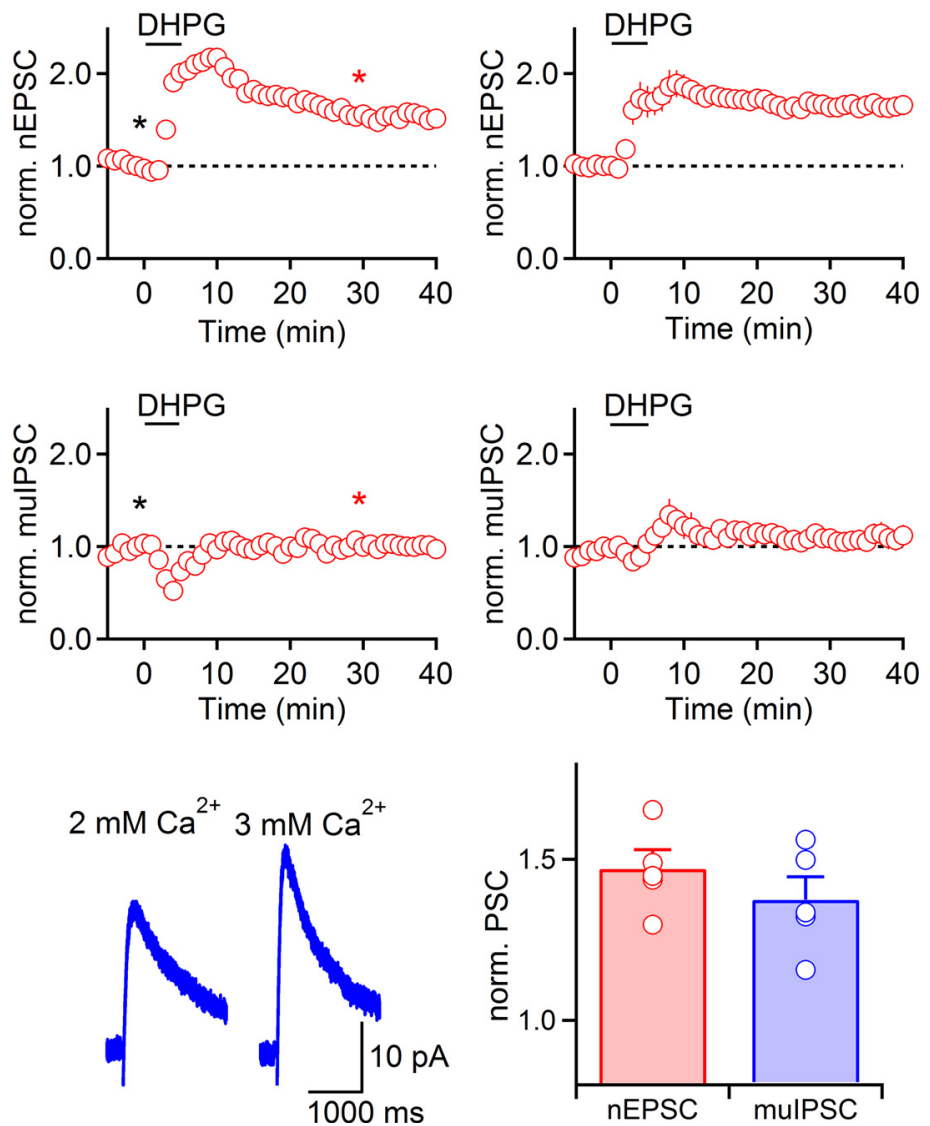

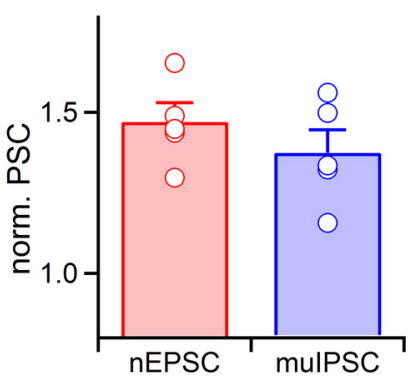

Figure 4. Group I mGluR activation by DHPG induces long-term potentiation of nEPSCS (mGluR-nLTP). $A$, Bath application of the selective Group I mGluR agonist DHPG (50 $\mu \mathrm{M}, 5 \mathrm{~min}$ ) induced long-term enhancement of nEPSCs $(n=7)$. TRN neurons were recorded with a Cs-based internal solution. Atropine (10 $\mu \mathrm{m})$ was included in the bath to block mAChRs. $B$, DHPG application did not lead to a persistent change of mulPSC amplitude $(n=7)$. Recordings were performed with a K-based internal solution. mulPS(s were isolated by blocking nAChR currents with DH $\beta E$ ( $500 \mathrm{~nm})$. $A$, $\boldsymbol{B}$, Left, Representative traces recorded in control (black) and $30 \mathrm{~min}$ following DHPG application (red). $\boldsymbol{A}, \boldsymbol{B}$, Middle, Representative experiments show time course of synaptic response before and following DHPG application. Individual values indicate average over 5 consecutive time points. *Time points of recordings shown on left. $A, B$, Right, Summary data, expressed as mean \pm SEM. $C$, Bath application of ACSF containing $3 \mathrm{~mm} \mathrm{Ca}{ }^{2+}$ to increase release probability $p$ led to comparable amplitude increases for $n E P S C s$ and mulPSCs. Left, Representative recordings of $n E P S C$ (red) and mulPSC (blue). Recordings of isolated nEPSCs and mulPSCs were obtained as described for $\boldsymbol{A}$ and $\boldsymbol{B}$. Right, Summary of increases in amplitude of $\mathrm{nEPSC}($ red, $n=5)$ and mulPSC (blue, $n=5$ ), normalized to values in $2 \mathrm{~mm} \mathrm{Ca}^{2+}$.

cubated in the PLC inhibitor U73122 (5 $\mu \mathrm{M})$. Under these conditions, DHPG led to a short-term increase in nEPSC amplitude similar to what was observed following TBOA application, but mGluR-nLTP was not induced ( $113 \pm 8 \%$ of baseline, $t=26-30$ $\min , n=5, p=0.55$, paired $t$ test; Fig. $5 A$ ). To examine whether increases in intracellular $\mathrm{Ca}^{2+}$ are critical for mGluR-nLTP, we included the $\mathrm{Ca}^{2+}$ chelator BAPTA (20 mM) in the internal solution to hold postsynaptic $\mathrm{Ca}^{2+}$ levels at $50-100 \mathrm{nM}$. As observed during TBOA application, DHPG induced a transient increase in nEPSC amplitude before values returned to baseline levels $(101 \pm 11 \%, t=26-30 \mathrm{~min}, n=5, p=0.85$, paired $t$ test; Fig. $5 B$ ). Together, these data suggest that the activation of PLC and increases in postsynaptic $\mathrm{Ca}^{2+}$ are both required for mGluR-nLTP.

\section{Activation of both mGluR1 and mGluR5 is required for mGluR-nLTP induction}

Our data described above indicate that transient increases in nicotinic synaptic strength following TBOA application require activation of both mGluR1 and mGluR5 (Fig. 1). To determine whether mGluR-nLTP is similarly dependent on both types of receptors, we quantified mGluR-nLTP induced by DHPG, in the presence of either CPCCOEt $(100 \mu \mathrm{M})$ or MPEP $(50 \mu \mathrm{M})$. In the presence of either antagonist, mGluR-nLTP was completely abolished (CPCCOEt: $91 \pm 11 \%$ of baseline, $t=26-30 \mathrm{~min}, n=5$, $p=0.70$, paired $t$ test; MPEP: $83 \pm 7 \%$ of baseline, $t=26-30$ $\min , n=5, p=0.14$, paired $t$ test; Fig. $6 A, B)$. Furthermore, activation of mGluR5 alone using the specific agonist CHPG (500 $\mu \mathrm{M}$ for $5 \mathrm{~min}$ ) did not enhance nEPSC amplitude ( $93 \pm 10 \%$ of baseline, $t=26-30 \mathrm{~min}, n=5, p=0.22$, paired $t$ test; Fig. $6 C$ ). Together, these data indicate that activation of both mGluR1 and mGluR5 is required for mGluR-nLTP.

To further establish that a synergistic interaction of mGluR1 and mGluR5 is necessary for the induction of mGluR-nLTP, we used two genetic mouse models that either lack mGluR5 throughout the brain or show strongly reduced mGluR5 expression restricted to GABAergic neurons in the forebrain, including TRN neurons (H.-C. Lu, unpublished observations). We found that mGluR-nLTP was absent ( $86 \pm$ $7 \%$ of baseline, $t=26-30 \mathrm{~min}, n=7, p=0.337$, paired $t$ test; Fig. $6 D)$ in $m$ GluR $5^{-1-}$ mice, whereas mGluR-nLTP could be reliably induced in WT littermates ( $159 \pm 14 \%$ of baseline, $t=$ $26-30 \min , n=4, p=0.036$, paired $t$ test; Fig. $6 D$ ). Similarly, mGluR-nLTP was absent in slices derived from GABAergic neuron-specific mGluR5 knock-out animals (94 $\pm 3 \%, t=$ 
A

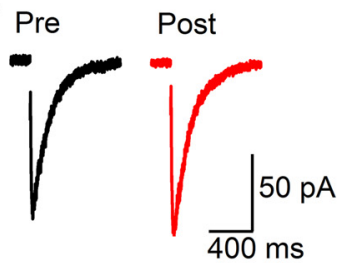

B

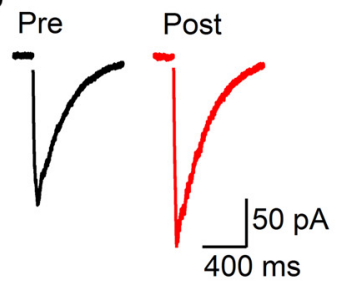

U73122

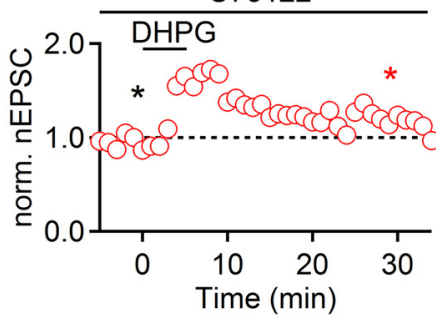

BAPTA

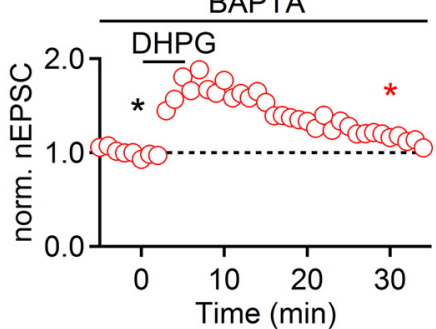

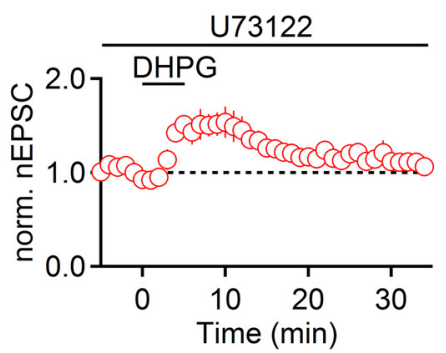

BAPTA

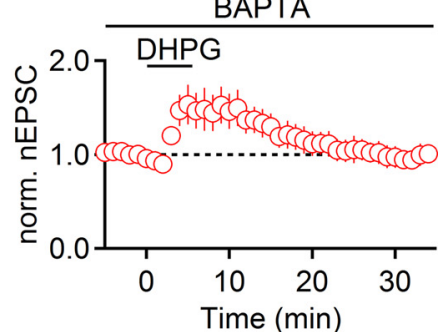

Figure 5. mGluR-nLTP depends on PLC and postsynaptic $\mathrm{Ca}^{2+}$ increases. Recordings were performed with a (s-based internal solution. $A$, No mGluR-nLTP was observed in the presence of the

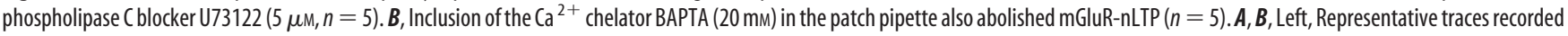
in control (black) and 30 min following DHPG application (red). $A, B$, Middle, Representative experiments show time course of nEPSC before and following DHPG application. Individual values indicate average over 5 consecutive time points. *Time points of recordings shown on left. $A, B$, Right, Summary data, expressed as mean \pm SEM.

A

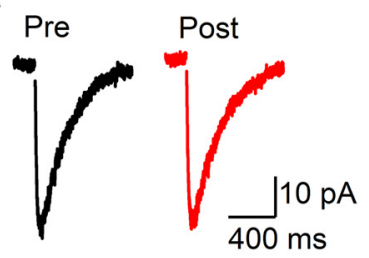

B

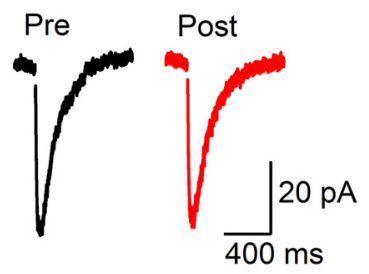

CPCCOEt

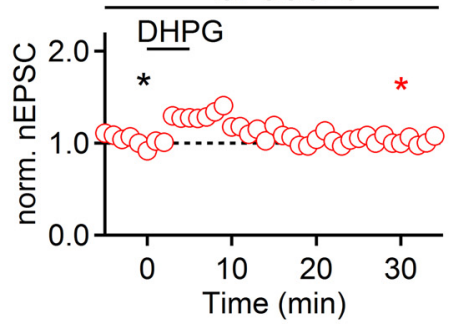

MPEP

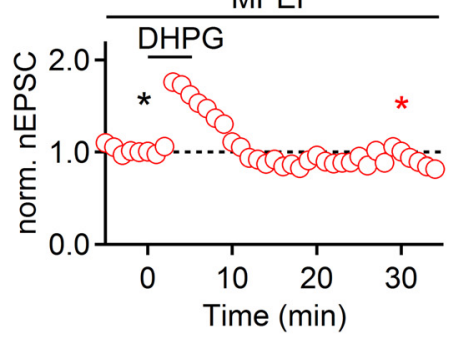

CPCCOEt
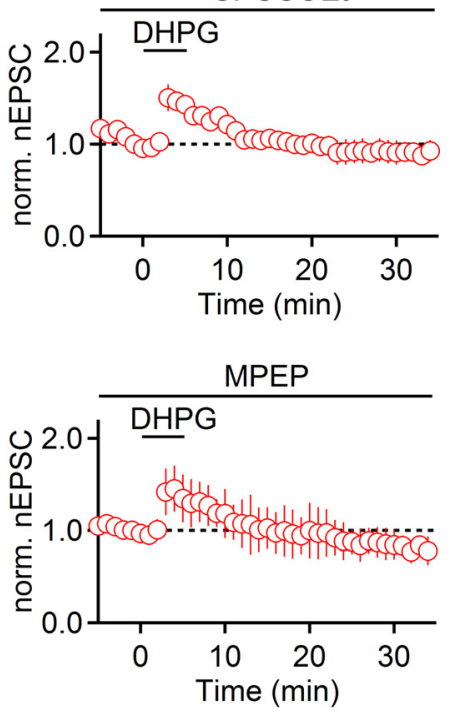

C

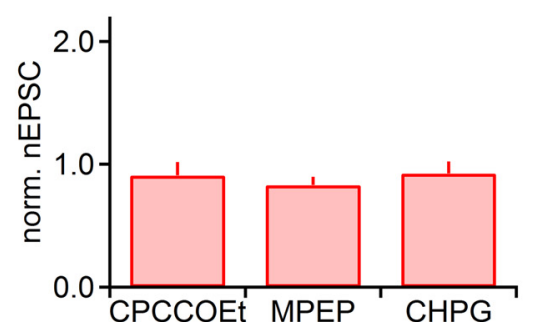

D

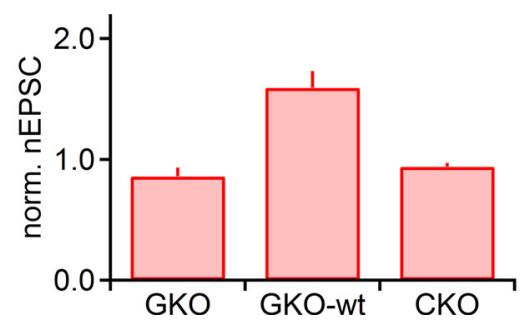

Figure 6. Activation of both $m G l u R 1$ and $m G$ luR5 is required for the induction of $m G$ luR-nLTP. Recordings were performed with a Cs-based internal solution. $A$, DHPG failed to evoke mGluR-nLTP in the presence of the mGluR1 antagonist CPCCOEt (100 $\mu \mathrm{M}, n=5)$. $\boldsymbol{B}$, In the presence of the mGluR5 antagonist MPEP $(50 \mu \mathrm{m})$, DHPG failed to evoke mGluR-nLTP $(n=5)$. $A, B$, Left, Representative traces recorded in control (black) and 30 min following DHPG application (red). $\boldsymbol{A}, \boldsymbol{B}$, Middle, Representative experiments show time course of $n$ EPSC before and following DHPG application. Individual values indicate average over 5 consecutive time points. ${ }^{*}$ Time points of recordings shown on left. $\boldsymbol{A}, \boldsymbol{B}$, Right, Summary data, expressed as mean \pm SEM. $\boldsymbol{C}$, Summary data quantifying the magnitude of mGluR-nLTP (measured at $t=26-30 \mathrm{~min}$ ) in the presence of CPCCOEt $(100 \mu \mathrm{m}, n=5)$ or MPEP $(50 \mu \mathrm{M}, n=5)$ and following application of the mGluR5 agonist CHPG (500 $\mu \mathrm{M}, 5$ $\min , n=5$ ) replacing DHPG. $D$, Summary data quantifying the magnitude of mGluR-nLTP (measured at $t=26-30 \mathrm{~min}$ ) in slices derived from mGluR5 knock-out mice (GKO, $n=7$ ), their WT littermates (GKO-wt, $n=4)$, and from GABAergic neuron specific mGluR5 knock-out mice (CKO, $n=3)$. 
A

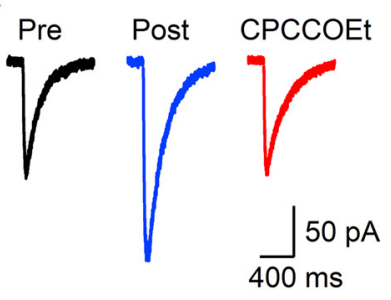

B

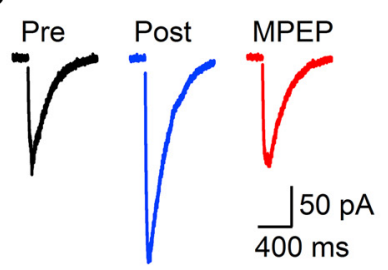

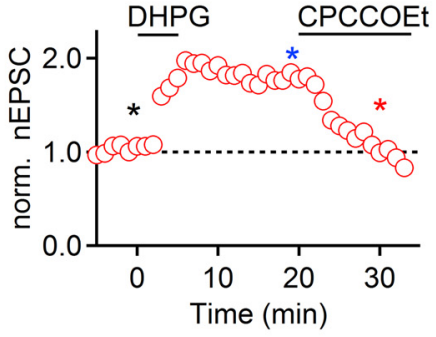
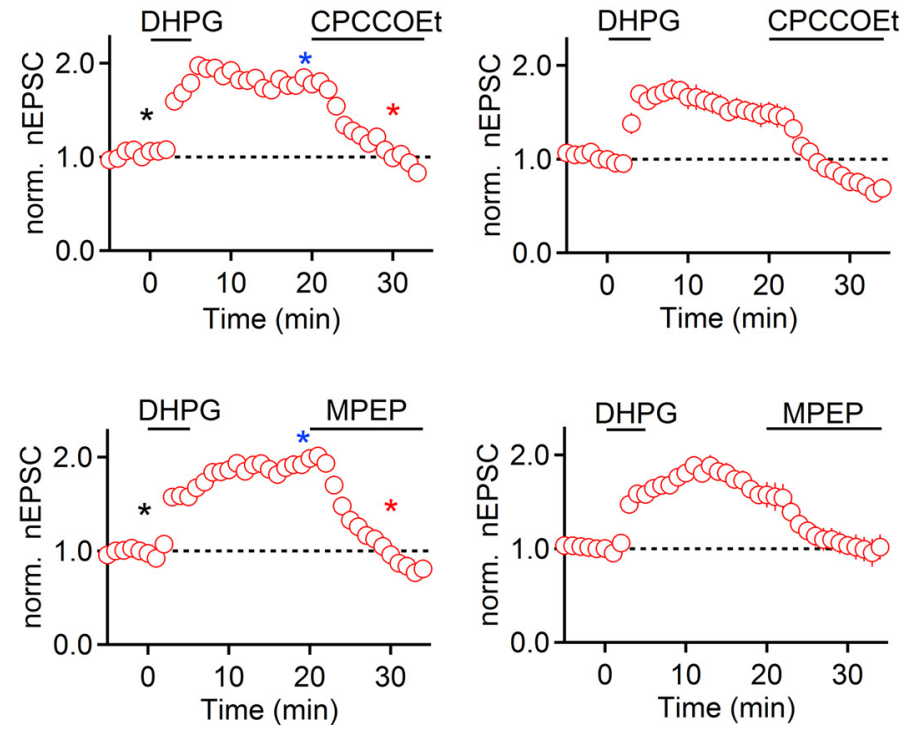

Figure 7. Expression of mGluR-nLTP requires mGluR1 and mGluR5 activity. Recordings were performed with a (s-based internal solution. $\boldsymbol{A}$, mGluR-nLTP was reversed following bath application of (PCCOEt (100 $\mu \mathrm{M}, n=5)$, which began 20 min after start of DHPG application. $\boldsymbol{B}$, mGluR-nLTP was reversed following bath application of MPEP (50 $\mu \mathrm{M}, n=5)$, which began 20 min after start of DHPG application. $\boldsymbol{A}, \boldsymbol{B}$, Left, Representative traces recorded in control (black), 20 min following start of DHPG application (blue), and 10 min following start of mGluR antagonist application (red). $\boldsymbol{A}, \boldsymbol{B}$, Middle, Representative experiments show time course of mGluR-nLTP before and following mGluR antagonist application. Individual values indicate average over 5 consecutive time points. *Time points of recordings shown on left. $\boldsymbol{A}, \boldsymbol{B}$, Right, Summary data, expressed as mean \pm SEM.

26-30 $\min , n=3$; Fig. $6 D$ ), indicating that the activation of mGluR5 expressed by TRN neurons is essential for mGluR-nLTP.

\section{Activation of mGluR1 and mGluR5 is required for mGluR-nLTP expression}

Previous studies have shown that Group I mGluRs can be involved in both induction and maintenance of long-term depression (LTD) of glutamatergic synapses (Palmer et al., 1997; Huang and Hsu, 2006; Volk et al., 2006). Having established that the induction of mGluR-nLTP requires activation of both mGluR1 and mGluR5, we next determined their respective roles in the maintenance of mGluR-nLTP by bath-applying either CPCCOEt $(100 \mu \mathrm{M})$ or MPEP $(50 \mu \mathrm{M}) 20$ min after mGluR-nLTP induction. Interestingly, both CPCCOEt ( $51 \pm 2 \%$ of mGluR-nLTP, $t=30 \mathrm{~min}, n=5, p=0.001$, paired $t$ test; Fig. 7A) and MPEP ( $64 \pm 7 \%$ of mGluR-nLTP, $t=30 \mathrm{~min}, n=5, p=0.036$, paired $t$ test; Fig. $7 B$ ) reversed mGluR-nLTP, and in the case of CPCCOEt, reduced nEPSC amplitude below control values, consistent with the critical role of mGluR1 activity under baseline conditions described above (Fig. 2). Thus, persistent activation of both mGluR1 and mGluR5 is required for mGluR-nLTP maintenance.

DHPG application can lead to a change in mGluR properties, resulting in persistent receptor activation in the absence of endogenous or exogenous ligand (Niswender and Conn, 2010; Lodge et al., 2013; Young et al., 2013), which could explain our results. Alternatively, incomplete washout of DHPG in our experiments might have led to a continued activation of mGluRs. However, as described above, lower doses of DHPG only led to a transient enhancement of nEPSCs, indicating that effective DHPG concentrations in our slice preparation rapidly decrease during washout. It is also possible that DHPG application might have led to persistent increases in excitability and neuronal activity, resulting in enhanced activation of mGluR 1 and mGluR5 due to increases in glutamate levels. To reveal possible increases in ambient glutamate levels following DHPG application, we measured NMDAR-mediated currents, in neurons held at $40 \mathrm{mV}$. We found that DHPG caused a transient increase in holding current (546.5 $\pm 178.3 \mathrm{pA}, n=6$; data not shown), which decayed rapidly to baseline levels ( tau $_{\text {decay }}=20.4 \pm 4.8 \mathrm{~s}$ ). Thus, under our experimental conditions, increases in glutamate levels appear to be brief, likely generated by the transient firing of presynaptic thalamic and cortical neurons depolarized by DHPG, making enhanced glutamate levels an unlikely mechanism of mGluR-nLTP. Instead, our data suggest that mGluR-nLTP is maintained by a persistent and ligandindependent activation of mGluR1 and mGluR5.

\section{Discussion}

Our studies have demonstrated a critical role of postsynaptic Group I mGluRs in dynamically regulating synaptic strength at cholinergic synapses in TRN neurons. We found that increases in ambient or synaptically evoked glutamate levels resulted in shortterm increases in cholinergic signaling, whereas DHPG-mediated activation of mGluRs led to persistent enhancement of cholinergic synaptic strength. Similar to several mGluR-dependent forms of LTP and LTD at glutamatergic synapses, mGluR-nLTP required increases in postsynaptic $\mathrm{Ca}^{2+}$ and the activation of PLC. Surprisingly, the activation of mGluR1 and mGluR5 was required for both induction and expression of mGluR-nLTP. To our knowledge, this is the first description of long-term synaptic plasticity at a cholinergic synapse in the mammalian CNS.

\section{Group I mGluR-dependent regulation of cholinergic synaptic transmission}

TRN neuronal dendrites express mGluR1 and mGluR5 (Godwin et al., 1996), and the activation of Group I mGluRs by either synaptic inputs or exogenous agonists has been shown to trigger changes in membrane potential (Cox and Sherman, 1999), oscillatory activity (Long et al., 2004; Blethyn et al., 2006), or longterm plasticity at electrical synapses interconnecting TRN 
neurons (Landisman and Connors, 2005). However, previous studies did not explore a role of individual subtypes in regulating neuronal or synaptic signaling. Here we show that activation of both mGluR1 and mGluR5 is required for short- and long-term forms of cholinergic synaptic plasticity. While both subtypes are canonically linked to $G_{q} / G_{11}$ and the activation of phospholipase $\mathrm{C}$, ultimately resulting in $\mathrm{Ca}^{2+}$ release from internal stores and the activation of PKC (Niswender and Conn, 2010), each receptor can control additional and separate signaling pathways, resulting in distinct functional roles (Hermans and Challiss, 2001; Mannaioni et al., 2001). In cases where both receptors are linked to a common physiological process, their combined activation often results in larger effects on membrane potential (Mori and Gerber, 2002) or synaptic plasticity (Gubellini et al., 2003). However, forms of synergistic signaling that require both subtypes to trigger any downstream effect as observed in the present study have rarely been documented (Le Duigou and Kullmann, 2011). The underlying mechanisms remain to be investigated. It is possible that only the combined activation of both receptors leads to a signal sufficiently large in magnitude to trigger downstream processes. Alternatively, mGluR1 and mGluR5 monomers might physically interact as heterodimers (Doumazane et al., 2011) or pairs of homodimers (Sevastyanova and Kammermeier, 2014), with transmitter binding to one receptor inducing G-protein activation in the other. Finally, nonlinear interactions might occur further downstream, mediated by distinct signaling cascades associated with both receptor subtypes.

Our findings indicate that CT afferent activity could be a critical mediator of mGluR-mediated cholinergic plasticity, at least on short time scales. CT projections (Jones, 2007) and cholinergic afferents from the $\mathrm{BF}$ and the brainstem (Hallanger and Wainer, 1988) both target the distal dendrites of TRN neurons, suggesting that synaptically recruited Group I mGluRs and nAChRs are part of the same functional domains. Cortical feedback might allow for more spatially confined control of cholinergic action. While the large volumes covered by individual cholinergic axonal projections (Wu et al., 2014) suggest that cholinergic inputs primarily convey global signals, plasticity of nicotinic signaling might be controlled more locally, enabled by activation of CT projections that contact TRN neurons in a highly topographic manner (Deschênes et al., 1998). A similar concept has been proposed for glutamatergic control of cholinergic signaling in prefrontal cortex (Sarter et al., 2014).

In addition, it remains possible that Group I mGluRs required for nicotinic synaptic plasticity are expressed extrasynaptically and are activated by increases in ambient glutamate. Consistent with this scenario, our own findings show a persistent activation of mGluR1, even under baseline conditions. This agrees with other studies showing that ambient glutamate in the TRN can tonically activate presynaptic mGluRs and NMDARs (Crabtree et al., 2013) or postsynaptic NR2C-containing NMDARs (Zhang et al., 2009), perhaps due to extrasynaptic release of glutamate or a slow uptake of synaptically released glutamate.

\section{Properties of mGluR-nLTP}

We found that the application of DHPG led to a persistent enhancement in cholinergic synaptic strength (mGluR-nLTP), which in contrast to transient forms of cholinergic potentiation required both increases in intracellular $\mathrm{Ca}^{2+}$ and activation of PLC. Although our results offer an important "proof of principle" for the existence of long-term forms of cholinergic synaptic plasticity, it remains unclear why mGluR-nLTP was not observed following increases in endoge- nous glutamate. It is possible that DHPG application surpassed a critical threshold level of Group I mGluR activation not reached with increases in endogenous glutamate, at least under our experimental conditions.

Our results show that mGluR-nLTP is expressed as an increase in nEPSC amplitude, whereas mAChR-mediated signaling remains unaffected, consistent with a postsynaptic expression mechanism rather than an increase in release probability. Longterm changes in nicotinic signaling could be mediated by a number of processes, including changes in nAChR kinetics, increased receptor trafficking, or more efficient clustering of $n A C h R s$ at the postsynaptic membrane. These processes are thought to be controlled by direct $\mathrm{nAChR}$ phosphorylation as well as by a number of nAChR-associated proteins (Jones et al., 2010). Future studies will be needed to identify the molecular cascades underlying cholinergic synaptic plasticity, here and elsewhere in the brain.

We found that persistent activation of Group I mGluRs is required for the maintenance phase of mGluR-nLTP, extending previous findings that have shown a critical role of Group I mGluRs in maintaining long-term cellular plasticity (Young et al., 2013) and LTD at glutamatergic synapses (Palmer et al., 1997; Huang and Hsu, 2006; Volk et al., 2006). It was shown previously that effective DHPG concentrations rapidly decrease following washout (Lodge et al., 2013; Young et al., 2013), suggesting that mGluR-nLTP is not mediated by the continued presence of exogenous agonist. In addition, we found that postsynaptic NMDAR-mediated currents rapidly decayed following DHPG application, indicating that DHPG-evoked increases in glutamate levels are highly transient and are therefore unlikely involved in mediating mGluR-nLTP. The most parsimonious explanation for the persistent activation of mGluR1 and mGluR5 is a change in receptor properties triggered by DHPG application. This could be a change in affinity to glutamate as reported for kainate receptors (Lauri et al., 2006), or more likely, a conformational change in the receptor itself leading to persistent activity in the absence of ligand (Hermans and Challiss, 2001). Such a change can be mediated by scaffolding proteins, such as Homerla, which is upregulated during synaptic activity and displaces Homer3, which under baseline conditions prevents persistent signaling (Ango et al., 2001; Kammermeier and Worley, 2007).

Regardless of the underlying mechanism, our results clearly indicate a role of both mGluR1 and mGluR5 during the maintenance phase of mGluR-nLTP. This differs from previous studies on glutamatergic synapses, which implicate either mGluR1 (Volk et al., 2006; Lodge et al., 2013) or mGluR5 alone (Huang and Hsu, 2006; Ronesi et al., 2012) in mediating LTD maintenance.

\section{Functional implications}

A possible functional role for mGluR-mediated nicotinic synaptic plasticity is intimately linked to the more general question of how cholinergic afferents regulate TRN neuronal firing and thus thalamic output to neocortex during distinct behavioral states. Because of the biphasic nature of cholinergic synaptic transmission (Sun et al., 2013), cholinergic inputs will shape TRN activity in distinct ways, dependent on the temporal pattern of afferent activity. Brief and synchronous activity will likely lead to nAChRdependent transient firing in many TRN neurons, mediated by cholinergic afferents with extensive axonal convergence and divergence (Sun et al., 2013; Pita-Almenar et al., 2014). Interestingly, BF cholinergic neurons in awake mice display nearsynchronous phasic responses following punishment or reward during an attention-demanding task (Hangya et al., 2015). Such activity patterns relayed by extensive BF projections to neocortex are thought to enable plastic changes in cortical circuits leading to 
learning and memory (Letzkus et al., 2011, 2015). BF cholinergic neurons also project extensively to TRN (Hallanger et al., 1987; Jourdain et al., 1989; Pita-Almenar et al., 2014), with at least a fraction of BF neurons forming contacts to both targets (Jourdain et al., 1989). This suggests that TRN might act as an additional mediator for BF-induced plasticity processes in the thalamocortical system, with mGluR-dependent changes in nicotinic signaling determining both strength and location of plasticity.

On the other hand, ongoing asynchronous activity in populations of cholinergic and noncholinergic BF neurons, as observed during periods of arousal and attention (Lee et al., 2005; Hangya et al., 2015), is thought to lead to an overall decrease in TRN neuronal firing, in part mediated by temporal summation of mAChR-mediated inhibition (Sun et al., 2013), ultimately resulting in disinhibition of relay cells and enabling more effective information flow to cortex (Thiele, 2009). However, the relative contributions of nAChR-mediated excitation and mAChRmediated inhibition vary dramatically for different TRN neurons (Sun et al., 2013), suggesting that, for any given pattern of BF afferent activity, specific networks of TRN neurons will increase their firing rates, whereas others will decrease their activity. Our findings show that Group I mGluRs can dynamically regulate cholinergic E-I ratio over distinct time scales, allowing for a context-dependent control of TRN network dynamics. Such functionally defined subnetworks could act independent of anatomically defined subnetworks (Halassa et al., 2014) and might allow TRN to dynamically control sensory information flow.

\section{References}

Agmon A, Connors BW (1991) Thalamocortical responses of mouse somatosensory (barrel) cortex in vitro. Neuroscience 41:365-379. CrossRef Medline

Ango F, Prézeau L, Muller T, Tu JC, Xiao B, Worley PF, Pin JP, Bockaert J, Fagni L (2001) Agonist-independent activation of metabotropic glutamate receptors by the intracellular protein Homer. Nature 411:962-965. CrossRef Medline

Arroyo S, Bennett C, Aziz D, Brown SP, Hestrin S (2012) Prolonged disynaptic inhibition in the cortex mediated by slow, non-alpha7 nicotinic excitation of a specific subset of cortical interneurons. J Neurosci 32: 3859-3864. CrossRef Medline

Arroyo S, Bennett C, Hestrin S (2014) Nicotinic modulation of cortical circuits. Front Neural Circuits 8:30. CrossRef Medline

Blethyn KL, Hughes SW, Tóth TI, Cope DW, Crunelli V (2006) Neuronal basis of the slow $(<1 \mathrm{~Hz})$ oscillation in neurons of the nucleus reticularis thalami in vitro. J Neurosci 26:2474-2486. CrossRef Medline

Bortone DS, Olsen SR, Scanziani M (2014) Translaminar inhibitory cells recruited by layer 6 corticothalamic neurons suppress visual cortex. Neuron 82:474-485. CrossRef Medline

Boucetta S, Cissé Y, Mainville L, Morales M, Jones BE (2014) Discharge profiles across the sleep-waking cycle of identified cholinergic, GABAergic, and glutamatergic neurons in the pontomesencephalic tegmentum of the rat. J Neurosci 34:4708-4727. CrossRef Medline

Chanda S, Xu-Friedman MA (2011) Excitatory modulation in the cochlear nucleus through Group I metabotropic glutamate receptor activation. J Neurosci 31:7450-7455. CrossRef Medline

Chao HT, Chen H, Samaco RC, Xue M, Chahrour M, Yoo J, Neul JL, Gong S, Lu HC, Heintz N, Ekker M, Rubenstein JL, Noebels JL, Rosenmund C, Zoghbi HY (2010) Dysfunction in GABA signalling mediates autismlike stereotypies and Rett syndrome phenotypes. Nature 468:263-269. CrossRef Medline

Cox CL, Sherman SM (1999) Glutamate inhibits thalamic reticular neurons. J Neurosci 19:6694-6699. Medline

Crabtree JW, Lodge D, Bashir ZI, Isaac JT (2013) GABAA, NMDA and mGlu2 receptors tonically regulate inhibition and excitation in the thalamic reticular nucleus. Eur J Neurosci 37:850-859. CrossRef Medline

Deschênes M, Veinante P, Zhang ZW (1998) The organization of corticothalamic projections: reciprocity versus parity. Brain Res Brain Res Rev 28:286-308. CrossRef Medline
Doumazane E, Scholler P, Zwier JM, Trinquet E, Rondard P, Pin JP (2011) A new approach to analyze cell surface protein complexes reveals specific heterodimeric metabotropic glutamate receptors. FASEB J 25:66-77. CrossRef Medline

Eggermann E, Kremer Y, Crochet S, Petersen CC (2014) Cholinergic signals in mouse barrel cortex during active whisker sensing. Cell Rep 9:1654-1660. CrossRef Medline

Gladding CM, Fitzjohn SM, Molnár E (2009) Metabotropic glutamate receptor-mediated long-term depression: molecular mechanisms. Pharmacol Rev 61:395-412. CrossRef Medline

Godwin DW, Van Horn SC, Eriir A, Sesma M, Romano C, Sherman SM (1996) Ultrastructural localization suggests that retinal and cortical inputs access different metabotropic glutamate receptors in the lateral geniculate nucleus. J Neurosci 16:8181-8192. Medline

Gu Z, Yakel JL (2011) Timing-dependent septal cholinergic induction of dynamic hippocampal synaptic plasticity. Neuron 71:155-165. CrossRef Medline

Gubellini P, Saulle E, Centonze D, Costa C, Tropepi D, Bernardi G, Conquet F, Calabresi P (2003) Corticostriatal LTP requires combined mGluR1 and mGluR5 activation. Neuropharmacology 44:8-16. CrossRef Medline

Halassa MM, Siegle JH, Ritt JT, Ting JT, Feng G, Moore CI (2011) Selective optical drive of thalamic reticular nucleus generates thalamic bursts and cortical spindles. Nat Neurosci 14:1118-1120. CrossRef Medline

Halassa MM, Chen Z, Wimmer RD, Brunetti PM, Zhao S, Zikopoulos B, Wang F, Brown EN, Wilson MA (2014) State-dependent architecture of thalamic reticular subnetworks. Cell 158:808-821. CrossRef Medline

Hallanger AE, Wainer BH (1988) Ultrastructure of ChAT-immunoreactive synaptic terminals in the thalamic reticular nucleus of the rat. J Comp Neurol 278:486-497. CrossRef Medline

Hallanger AE, Levey AI, Lee HJ, Rye DB, Wainer BH (1987) The origins of cholinergic and other subcortical afferents to the thalamus in the rat. J Comp Neurol 262:105-124. CrossRef Medline

Hangya B, Ranade SP, Lorenc M, Kepecs A (2015) Central cholinergic neurons are rapidly recruited by reinforcement feedback. Cell 162 : 1155-1168. CrossRef Medline

Hassani OK, Lee MG, Henny P, Jones BE (2009) Discharge profiles of identified GABAergic in comparison to cholinergic and putative glutamatergic basal forebrain neurons across the sleep-wake cycle. J Neurosci 29: 11828-11840. CrossRef Medline

Hasselmo ME, Sarter M (2011) Modes and models of forebrain cholinergic neuromodulation of cognition. Neuropsychopharmacology 36:52-73. CrossRef Medline

Hermans E, Challiss RA (2001) Structural, signalling and regulatory properties of the Group I metabotropic glutamate receptors: prototypic family C G-protein-coupled receptors. Biochem J 359:465-484. CrossRef Medline

Huang CC, Hsu KS (2006) Sustained activation of metabotropic glutamate receptor 5 and protein tyrosine phosphatases mediate the expression of (S)-3,5-dihydroxyphenylglycine-induced long-term depression in the hippocampal CA1 region. J Neurochem 96:179-194. CrossRef Medline

Jones AK, Buckingham SD, Sattelle DB (2010) Proteins interacting with nicotinic acetylcholine receptors: expanding functional and therapeutic horizons. Trends Pharmacol Sci 31:455-462. CrossRef Medline

Jones EG (2007) The thalamus, 2nd Ed. Cambridge; NY: Cambridge UP.

Jourdain A, Semba K, Fibiger HC (1989) Basal forebrain and mesopontine tegmental projections to the reticular thalamic nucleus: an axonal collateralization and immunohistochemical study in the rat. Brain Res 505: 55-65. CrossRef Medline

Kammermeier PJ, Worley PF (2007) Homer la uncouples metabotropic glutamate receptor 5 from postsynaptic effectors. Proc Natl Acad Sci U S A 104:6055-6060. CrossRef Medline

Kim U, Sanchez-Vives MV, McCormick DA (1997) Functional dynamics of GABAergic inhibition in the thalamus. Science 278:130-134. CrossRef Medline

Landisman CE, Connors BW (2005) Long-term modulation of electrical synapses in the mammalian thalamus. Science 310:1809-1813. CrossRef Medline

Lauri SE, Vesikansa A, Segerstråle M, Collingridge GL, Isaac JT, Taira T (2006) Functional maturation of CA1 synapses involves activitydependent loss of tonic kainate receptor-mediated inhibition of glutamate release. Neuron 50:415-429. CrossRef Medline

Le Duigou C, Kullmann DM (2011) Group I mGluR agonist-evoked long- 
term potentiation in hippocampal oriens interneurons. J Neurosci 31: 5777-5781. CrossRef Medline

Lee MG, Hassani OK, Alonso A, Jones BE (2005) Cholinergic basal forebrain neurons burst with theta during waking and paradoxical sleep. J Neurosci 25:4365-4369. CrossRef Medline

Letzkus JJ, Wolff SB, Meyer EM, Tovote P, Courtin J, Herry C, Lüthi A (2011) A disinhibitory microcircuit for associative fear learning in the auditory cortex. Nature 480:331-335. CrossRef Medline

Letzkus JJ, Wolff SB, Lüthi A (2015) Disinhibition, a circuit mechanism for associative learning and memory. Neuron 88:264-276. CrossRef Medline

Lodge D, Tidball P, Mercier MS, Lucas SJ, Hanna L, Ceolin L, Kritikos M, Fitzjohn SM, Sherwood JL, Bannister N, Volianskis A, Jane DE, Bortolotto ZA, Collingridge GL (2013) Antagonists reversibly reverse chemical LTD induced by Group I, Group II and Group III metabotropic glutamate receptors. Neuropharmacology 74:135-146. CrossRef Medline

Long MA, Landisman CE, Connors BW (2004) Small clusters of electrically coupled neurons generate synchronous rhythms in the thalamic reticular nucleus. J Neurosci 24:341-349. CrossRef Medline

Lüscher C, Huber KM (2010) Group 1 mGluR-dependent synaptic longterm depression: mechanisms and implications for circuitry and disease. Neuron 65:445-459. CrossRef Medline

Mannaioni G, Marino MJ, Valenti O, Traynelis SF, Conn PJ (2001) Metabotropic glutamate receptors 1 and 5 differentially regulate CA1 pyramidal cell function. J Neurosci 21:5925-5934. Medline

McAlonan K, Cavanaugh J, Wurtz RH (2006) Attentional modulation of thalamic reticular neurons. J Neurosci 26:4444-4450. CrossRef Medline

Monory K, Massa F, Egertová M, Eder M, Blaudzun H, Westenbroek R, Kelsch W, Jacob W, Marsch R, Ekker M, Long J, Rubenstein JL, Goebbels S, Nave KA, During M, Klugmann M, Wölfel B, Dodt HU, Zieglgänsberger W, Wotjak CT, et al. (2006) The endocannabinoid system controls key epileptogenic circuits in the hippocampus. Neuron 51:455-466. CrossRef Medline

Mori M, Gerber U (2002) Slow feedback inhibition in the CA3 area of the rat hippocampus by synergistic synaptic activation of mGluR1 and mGluR5. J Physiol 544:793-799. CrossRef Medline

Muñoz W, Rudy B (2014) Spatiotemporal specificity in cholinergic control of neocortical function. Curr Opin Neurobiol 26:149-160. CrossRef Medline

Ni KM, Hou XJ, Yang CH, Dong P, Li Y, Zhang Y, Jiang P, Berg DK, Duan S, Li XM (2016) Selectively driving cholinergic fibers optically in the thalamic reticular nucleus promotes sleep. Elife 5:e10382. CrossRef Medline

Niswender CM, Conn PJ (2010) Metabotropic glutamate receptors: physiology, pharmacology, and disease. Annu Rev Pharmacol Toxicol 50: 295-322. CrossRef Medline

Palmer MJ, Irving AJ, Seabrook GR, Jane DE, Collingridge GL (1997) The Group I mGlu receptor agonist DHPG induces a novel form of LTD in the CA1 region of the hippocampus. Neuropharmacology 36:1517-1532. CrossRef Medline
Pinault D (2004) The thalamic reticular nucleus: structure, function and concept. Brain Res Brain Res Rev 46:1-31. CrossRef Medline

Pinto L, Goard MJ, Estandian D, Xu M, Kwan AC, Lee SH, Harrison TC, Feng G, Dan Y (2013) Fast modulation of visual perception by basal forebrain cholinergic neurons. Nat Neurosci 16:1857-1863. CrossRef Medline

Pita-Almenar JD, Yu D, Lu HC, Beierlein M (2014) Mechanisms underlying desynchronization of cholinergic-evoked thalamic network activity. J Neurosci 34:14463-14474. CrossRef Medline

Ronesi JA, Collins KA, Hays SA, Tsai NP, Guo W, Birnbaum SG, Hu JH, Worley PF, Gibson JR, Huber KM (2012) Disrupted Homer scaffolds mediate abnormal mGluR5 function in a mouse model of fragile X syndrome. Nat Neurosci 15:431-440. CrossRef Medline

Sarter M, Lustig C, Howe WM, Gritton H, Berry AS (2014) Deterministic functions of cortical acetylcholine. Eur J Neurosci 39:1912-1920. CrossRef Medline

Sevastyanova TN, Kammermeier PJ (2014) Cooperative signaling between homodimers of metabotropic glutamate receptors 1 and 5. Mol Pharmacol 86:492-504. CrossRef Medline

Sun YG, Pita-Almenar JD, Wu CS, Renger JJ, Uebele VN, Lu HC, Beierlein M (2013) Biphasic cholinergic synaptic transmission controls action potential activity in thalamic reticular nucleus neurons. J Neurosci 33:20482059. CrossRef Medline

Thiele A (2009) Optimizing brain processing. Nat Neurosci 12:1359-1360. CrossRef Medline

Volk LJ, Daly CA, Huber KM (2006) Differential roles for group 1 mGluR subtypes in induction and expression of chemically induced hippocampal long-term depression. J Neurophysiol 95:2427-2438. CrossRef Medline

Whitehouse PJ, Price DL, Struble RG, Clark AW, Coyle JT, Delon MR (1982) Alzheimer's disease and senile dementia: loss of neurons in the basal forebrain. Science 215:1237-1239. CrossRef Medline

Wimmer RD, Schmitt LI, Davidson TJ, Nakajima M, Deisseroth K, Halassa MM (2015) Thalamic control of sensory selection in divided attention. Nature 526:705-709. CrossRef Medline

Woolf NJ, Butcher LL (2011) Cholinergic systems mediate action from movement to higher consciousness. Behav Brain Res 221:488-498. CrossRef Medline

Wu H, Williams J, Nathans J (2014) Complete morphologies of basal forebrain cholinergic neurons in the mouse. Elife 3:e02444. CrossRef Medline

Young SR, Chuang SC, Zhao W, Wong RK, Bianchi R (2013) Persistent receptor activity underlies Group I mGluR-mediated cellular plasticity in CA3 neuron. J Neurosci 33:2526-2540. CrossRef Medline

Zaborszky L (2002) The modular organization of brain systems. Basal forebrain: the last frontier. Prog Brain Res 136:359-372. CrossRef Medline

Zhang Y, Llinas RR, Lisman JE (2009) Inhibition of NMDARs in the nucleus reticularis of the thalamus produces delta frequency bursting. Front Neural Circuits 3:20. CrossRef Medline 